\title{
$\bullet$ IJCRR \\ Section: Healthcare \\ Meaning of Life and Emotional Ventilation of Mothers having Children with Autism Spectrum Disorder
} ISI Impact Factor (2019-20): 1.628 IC Value (2019): 90.81 SJIF (2020) $=7.893$

\section{Sagayaraj K' ${ }^{1}$, Gopal CNR ${ }^{1}$, Karthikeyan $\mathbf{S}^{2}$}

'Counselling Psychology, Faculty of Allied Health Sciences (FAHS), Chettinad Hospital and Research Institute (CHRI), Chettinad Academy of Research and Education (CARE), Kelambakkam, Chennai, Tamil Nadu, India.

${ }^{2}$ Lecturer\& Head in Charge, Department of Clinical Psychology, National Institute for Empowerment of Persons with Multiple Disabilities (Divyangjan), East Coast Road, Muttukadu, Kovalam Post, Chennai, Tamil Nadu, India.

\section{ABSTRACT}

Introduction: Autism Spectrum Disorder (ASD) is a range of neurodevelopmental related mental disorder which affects the individual's social interactions, communication and also causing the comorbid condition of repetitive behaviour, self-injurious behaviour, and developmental delays. It has been identified that mothers having children with autism have a higher level of parenting-related stresses and longing for better physical, social and mental health. Meaning of life comprises of "Who are we?, Why are we here ?, What is the purpose of our life? and what is the reason we are living for ?" in the context of scientific theories, philosophical and theological explanations. Mothers with special children spend most of their life by providing supportive care to their children and fail to realize their meaning of life.

Methods: To understand the purpose of life of mothers who are having children with ASD, The Meaning of Life Questionnaire developed by Steger M. F(2006) was administered to 15 mothers who are having children with ASD followed by a semi-structured interview. An overall perceptive was reported in this study.

Result: The result indicates that there was no significant difference in presence and search state in the meaning of life of mothers having children with ASD.

Conclusion: The participants from this study disclosed that they have not valued the meaning and purpose in life which can be addressed by psychological counselling and intervention.

Key Words: Autism, Counselling, Disability, Emotion, Meaning of life, Parenting

\section{INTRODUCTION}

The term "meaning of life" is commonly used in various contexts and has no clear definition. Many authors have described the experience of one's life as meaningful based on their feeling of integration and relatedness or a feeling of fulfilment and significance. ${ }^{1,2}$ When someone stating that he or she has meaning in their life, It implies that they have committed to the values, believes and positively committed to some core concept which provides a framework or directive goal to view their life in fulfilment as a feeling of integration, relatedness or significance. ${ }^{3,4}$ Parenthood is one of the most difficult jobs in everyone's life because it creates the new chapter in their life story. It invigorates another self in them something that they did not know was there until they had children. It also gives them a new sense of purpose and

\section{Corresponding Author:}

K. Sagayaraj, Counselling Psychology, Faculty of Allied Health Sciences (FAHS), Chettinad Hospital and Research Institute (CHRI), Chettinad Academy of Research and Education (CARE), Kelambakkam, Chennai, Tamil Nadu, India; Email: harrysagayaraj@gmail.com.

ISSN: $2231-2196$ (Print)

ISSN: $0975-5241$ (Online)

Received: 08.11 .2020

Revised: 12.01 .2021 meaning in life. As a parent, they tend to encounter love and passion for their children that they have never experienced before. ${ }^{5}$ There is a vast number of studies that confirms that the parents of special need children experience a higher level of stress, anxiety and depression. ${ }^{6,7}$ The recent study indicates that they experience a mixture of joy and sorrow with the presence of a child with a special need. ${ }^{8,10} \mathrm{All}$ human beings are craving for the meaning and true purposes of their life. In the parenting phase, every parent expects to have an average child who does not have any physical and psychological deficiency but when they have the special child they feel helpless, stressed and lose their purposes in life. ${ }^{11}$ Research shows that the meaning of life can be viewed in two broader dimensions thus, existence and search for meaning. ${ }^{12}$

Emotional ventilation is an art and essentials of our lives. Emotions in general will add importance and structure to our 
feelings and without these emotional expressions, we would resemble robots. How we feel and express emotions play a major role in physical and mental functioning. Emotional ventilation is the core of the healthy body, mind and soul. It is a sign of good health and strength rather than weakness. ${ }^{13}$ Mothers having children with special needs find no time and energy for the continuous caretaking of their children which leave them more stressed, helpless and hopeless in life. Hence, to develop a greater understanding of the lives of families with special needs children especially in the condition of ASD in terms of the meaning of life this study was carried out.

\section{AIM}

The study aims to analyze the meaning of life and emotional expression of mothers having children with an autism spectrum disorder.

\section{METHODOLOGY}

\section{Hypothesis for the study}

There will be no significant difference in the presence and search state on the meaning of life of the mothers having children with an autism spectrum disorder.

Research Design: Ex post facto research design was adopted for this study.

Sampling: Purposive sampling method was used in this study. Participants who were fulfilling the following inclusion criteria were only selected. The basic demographic details like age, education, family type, religion and socio-economic status were collected. All the participants were from the rural village of Kanchipuram district such as Kanathur, Mutthukadu and Kovalam located in Tamil Nadu, India.

\section{Inclusion Criteria:}

- Mothers who were having children with ASD between the age of 5 to 10 years were included.

- Mothers with no psychiatric conditions were only included.

Exclusion Criteria: Mothers with serious physical and psychiatric problems, not being primary caregivers were excluded.

\section{Tool Used:}

The Meaning of life Questionnaire (MLQ). Steger, M. F (2006). It assesses two dimensions of meaning in life (Presence \& Search) using 10 items rated on a seven-point scale from "Absolutely True" to "Absolutely Untrue." (i) Presence subscale scoring is done by adding items 1, 4, 5, 6 and 9 . Scores range between 5 to 35. (ii) Search subscale scoring was done by adding items $2,3,7,8$ and 10 . Scores range between 5 to 35. The internal consistency of the scale was found to be Presence (0.86) and Search (0.87) with good reliability. The scale is found to have good convergent, discriminant validity. ${ }^{12}$

\section{Scoring Interpretation}

The below interpretation is a probabilistic guess about the areas of life based on the MLQ scoring. Numerous studies also confirmed the same but it cannot be considered as a diagnostic tool for labelling their opinion about life. The context meaning of life differs from a different cultural and religious point of view.

I. If the score is above 24 on Presence and also above 24 on search then it can be inferred that, "They feel that life has value, meaning and purpose. Yet still openly exploring the meaning or purpose.

II. If the score is above 24 on Presence and below 24 on search, they feel their life has valued meaning and purpose, and are not actively exploring that meaning or seeking meaning in their life.

III. If the score is below 24 on Presence and above 24 on search, they probably do not feel their life has a valued meaning and purpose, and they are actively searching for something or someone that will give their life meaning of purpose.

IV. If the score is below 24 on Presence and also below 24 on search, they probably do not feel their life has a valued meaning and purpose, and are not actively exploring the meaning or seeking meaning in their life.

\section{Procedure}

All the participants were mothers of children with autism spectrum disorder and they were approached individually. Voluntary participation and the right to withdraw from the study was informed. After obtaining consent from the participants the MLQ questionnaire was used followed by the semi-structured interview. Initially, the participants were asked about how they were feeling about their current life situation, where it was meaningful in their point of view and was there any possibility of finding fulfilment in their life despite having a child with ASD. They were also encouraged to ventilate the family problems and emotional distress, issues in parenting the child with ASD. The interview lasted for about 15 to 20 minutes for each parent. After the personal semi-structured interview session they were thanked for their participation.

\section{Ethical Consideration}

This study was carried out with the approval of the Institutional Human Ethics Committee of Chettinad Academy of Research and Education (216/IHEC/Nov 2020), Kelambakkam, Chennai, Tamil Nadu, India as a part of the doctoral research. 
Statistical Analysis: The collected data was analyzed by using the SPSS version 20. Descriptive statistics and t-test was incorporated for the data analysis.

\section{RESULTS AND DISCUSSION}

\begin{tabular}{|c|c|c|c|c|}
\hline Dimensions & Mean & SD & $t$ & $\mathbf{P}$ \\
\hline Presence & 22.06 & 3.84 & $3.00 * \mathrm{NS}$ & 0.7 \\
\hline Search & 22.66 & 6.70 & & \\
\hline
\end{tabular}

$\mathrm{P}<0.05$ * $\mathrm{t}$ value is not significant at 0.05 level

The results indicate that the $t$ value of 3.00 was found to be non-significant at the 0.05 significant level hence hypothesis 1 is accepted. From the scoring procedure, it can be inferred that their presence and search state is below the expected score, which indicates that the selected samples of mothers having children with ASD have not valued meaning and purpose in their life and also not seeking actively the fulfillment of their life.

During the semi-structured interview, the mothers had emphasized the physical and emotional distress that they have undergone in parenting their child. Studies show the present state in one's life is associated with better physical and emotional wellbeing which is generally lacking in parents with a special child. ${ }^{15,17}$ The mean score of both presence and search was found to be 22 in the selected samples and as per interpretation, it can be inferred that selected mothers having children with ASD have not valued their meaning in life and also not keenly looking for the same. When asking about their futuristic plan in life they all stressed upon good wellbeing of their children and some of them even hoping for a complete cure from ASD. Even though they were educated about the child's condition and prolonged comprehensive care, they were just anticipating the miracle of complete cure from ASD as the child is growing older. According to the meaning of the life refers to their child's normalized physical functioning and recovery from the mental illness. They value nothing more important in their life than their child's well-being.

For a longer period, they misunderstood autism with mental retardation and was getting the available medical and psycho rehabilitation therapy which has taken their money, time and energy. To get a clear diagnosis of autism itself took nearly about 2 to 3 years. The mothers who were interviewed were from low and middle socioeconomic backgrounds, and they revealed their best financial plan was to feed the child three meals a day and no health insurance, savings were planned due to the low income of the family. During the interview session, they had ventilated the burden of having a child with ASD. Their self-confidence and quality of life were severely affected due to the condition of having a child with ASD. ${ }^{18,19}$ While explaining their problems they also mentioned the love and care that they show to make the child understand the emotional care of the mother. From being conceived with a child to birth, and from identifying the condition of autism to caretaking daily all these mothers played a vital role in the child comprehensive development.

\section{CONCLUSION}

The present findings of this investigation reveal that mothers of children with ASD do not find value, meaning and purpose in life. From the responses of the participants, we could understand that the mothers of ASD children would feel happy and find meaning in life only when their children get good physical and mental well-being. It is a challenging task for the mental health care professionals like psychologists, psychiatrists to address the parents with special children to find the purposes in their life. It is a need of the hour which supposed to be addressed in the form of counselling, psychotherapy and intervention.

Limitations and Future Directions: Meaning of life is more of one's personal opinion based on cultural, religious aspects and differ from environmental, socio-economic status. Considering the small number of participants of mothers having children with ASD, the result cannot be generalized for the larger population. An attempt of measuring the meaning of life with good psychometric properties allows a more nuanced analysis of their lifestyle and expectations. The Theotherwell-being components can be administered and studied in correlating with MLQ for developing better training, intervention for the mothers having children with ASD.

Implications: After an effective training program for the parents who are having special children such as autism spectrum disorder, the meaning of life questionnaire can be administered with appropriate counselling techniques to create a positive attitude towards life and valuing the meaning and purpose of it. In addition, the questionnaire could also be used to gather information about their expectations in life and assess successful therapy outcomes for the same

Conflict of Interest: None

Source of Funding: Chettinad Academy of Research and Education, Junior Research Fellowship (CARE - JRF) fund.

\section{ACKNOWLEDGEMENT}

The corresponding author would like to thank and acknowledge Chettinad Academy of Research and Education, Junior 
Research Fellowship (CARE - JRF) for supporting this work. He would also like to express his gratitude to the doctoral committee members Prof. Dr. R.Murugesan, Director - Research, CARE and Prof. Dr. OT. Sabari Sridhar, Head-Department of Psychiatry, CHRIfor their valuable suggestions and support during the work.

\section{Author's Contribution:}

Conceived and designed the study: Gopal CNR, Sagayaraj K

Semi-Structured Interview: Karthikeyan S, Sagayaraj K

Statistical analysis and writing original draft: Sagayaraj K

Writing - Review \&Editing: Gopal CNR, Karthikeyan S

\section{REFERENCES}

1. Weisskopf JE. Mental health and intention. J Psychol. 1968;69(1):101-106.

2. Maslow AM. Religions, Values, and Peak Experiences; Viking Press, 1964.pp 11.

3. Fabry J. The Pursuit of Meaning; Beacon Press. 1968:1-33.

4. Battista J, Almond R. The development of meaning in life. Psychi. 1973;36(4):409-27.

5. Hilt C. The Definition of Motherhood. Huffpost. Accessed on 05 Nov 2020. https://www.huffpost.com/entry/the-definition-ofmotherhood b 9734120

6. Blacher J, Neece CL, Paczkowski E. Families and intellectual disability. Curr Opin Psych. 2005;18(5):507-513.

7. Howie DR, McKenzie K. Diagnosis, information and stress in parents of children with a learning disability. Lear DisabPract. 2007;10: 28-33.

8. Kearney PM, Griffin T. Between joy and sorrow: being a parent of a child with a developmental disability. J Adv Nursing. 2001;34(5):582-92.
9. Little L, Clark RR. Wonders and Worries of parenting a child with Asperger Syndrome and nonverbal learning disorder. MCN: Am J Matern Child Nurs. 2006;31:39-44.

10. Trute B, Hiebert-Murphy D, Levine K. Parental appraisal of the family impact of childhood developmental disability: times of sadness and times of joy. J Intellect Dev Disabil. 2007;32(1):1-9.

11. Hirsch KH, Paquin D. The Stress of the Situation has Changed us Both: A Grounded Theory Analysis of the Romantic Relationship of Parents Raising Children with Autism. J Child Fam Stud. 2019; 28 (10):2673-2689.

12. Steger MF, Frazier P, Oishi S, Kaler M. The meaning in life questionnaire: Assessing the presence of and search for meaning in life. J Couns Psychol. 2006;53(1), 80-93.

13. Lee J, Lynn F. Mental health and well-being of parents caring for a ventilator-dependent child. Nurs Child Young People. 2017;29(5):33-40

14. Behera S. Emotional Ventilation: Necessity and uses. OnlineTherapy. Accessed on Nov 5, 2020. https://www.online-therapy. $\mathrm{com} / \mathrm{blog} /$ emotional-ventilation-necessity-uses/

15. Brassai L, Piko BF, Steger MF. Meaning in life: is it a protective factor for adolescents' psychological health? Int J Behav Med. 2011;18(1):44-51.

16. Steger MF, Fitch MA, Donnelly J, Rickard CM. Meaning in life and health: Proactive health orientation links meaning in life to health variables among American undergraduates. J Happiness Stud. 2015;16 (3), 583-597.

17. Estes A, Munson J, Dawson G, Koehler E. Parenting stress and psychological functioning among mothers of preschool children with autism and developmental delay. Autism. 2009;13(4):37587.

18. Karthikeyan S, Sivakumar V, Gopal CNR, Sagayaraj K. General Well-being and Self-Concept of Mothers having children with Multiple Disabilities. J Psyc Resea.2019; 63(1), 39-45.

19. Anderson LS. Mothers of children with special health care need: documenting the experience of their children's care in the school setting. J Sch Nurs. 2009;25(5):342-351. 